\title{
Spolni stereotipi in diskriminacija žensk na trgu dela: psihološki pogled
}

\author{
Mojca Svetek*, Ekonomska fakulteta, Univerza v Ljubljani
}

Povzetek: Pričujoči prispevek je pregled spoznanj (socialne) psihologije na področju diskriminacije žensk na trgu dela in delovnih mestih. Prispevek pojasnjuje, kako spolni stereotipi vplivajo na zaznavanje žensk in moških, pričakovanja na delovnem mestu in različne standarde ocenjevanja žensk in moških. Izpostavi, kateri psihološki mehanizmi so ključni pri vzdrževanju diskriminacije na trgu dela, in predstavi, kakšne so napovedi razvoja spolnih stereotipov v prihodnosti. Članek v pretežni meri obravnava ovire, s katerimi se ženske soočajo pri dostopanju do vodstvenih položajev, saj je ta vidik v psihološki literaturi do sedaj prejel največ pozornosti, kljub temu pa obravnavani mehanizmi diskriminacije niso omejeni na zgornjo plast trga dela.

Ključne besede: spolni stereotipi, ocenjevanje uspešnosti, opravičevanje diskriminacije, vodstveni položaji

\section{Gender stereotypes and discrimination against women in the labour market: a psychological perspective}

\author{
Mojca Svetek*, Faculty of Economics, University of Ljubljana, Slovenia
}

\begin{abstract}
This paper provides an overview of (social) psychological evidence of the gender-based workplace and labour market discrimination. The article discusses how gender stereotypes produce gendered employee perceptions, workplace expectations and standards of evaluations. It explains which psychological mechanisms are crucial in the maintenance of discrimination in the labour market and summarizes research findings on future development of gender stereotypes. The article mainly refers to the obstacles that women face in accessing management positions, since this issue received the most attention in psychological literature. Nevertheless, the mechanisms of discrimination presented in this review are not limited to the upper layer of the labour market.
\end{abstract}

Keywords: gender stereotypes, performance evaluation, discrimination justification, leadership positions

\footnotetext{
*Naslov/Address: Mojca Svetek, Ekonomska fakulteta, Univerza v Ljubljani, Kardeljeva ploščad 17, 1000 Ljubljana, e-mail: mojca.svetek@ef.uni-lj.si

Članek je licenciran pod pogoji Creative Commons Attribution 4.0 International licence. (CC-BY licenca). The article is licensed under a Creative Commons Attribution 4.0 International License (CC-BY license).
} 
Pri proučevanju diskriminacije se (socialna) psihologija že tradicionalno močno opira na spoznanja o stališčih do različnih skupin, še posebej o stereotipih in predsodkih. Stereotipi označujejo asociacije in pripisovanje specifičnih značilnosti posamezni socialni skupini, medtem ko se predsodki nanašajo na splošno (o)vrednotenje socialne skupine. S tem stereotipi in predsodki predstavljajo osnovo in upravičilo za diskriminacijo, ki označuje pristransko vedenje in obravnavo določene socialne skupine ali njenih članov.

Diskriminacija je lahko institucionalizirana, vendar pa se večina diskriminacij na trgu dela oziroma delovnem mestu ne zgodi zaradi formaliziranih diskriminatornih politik, pravil oziroma praks (na strukturni ravni), ampak se diskriminacija najpogosteje dogaja na subtilen način (na interakcijski ravni), npr. s selektivno uporabo specifičnih kriterijev pri zaposlovanju, vrednotenju dela, ugotavljanju napak pri delu in podobno (Bobbit-Zehr, 2011; Ridgeway, 1997). Prav tako diskriminacije posamezniki ne izvajajo vedno namerno, ampak tudi tisti, ki eksplicitno izražajo socialne, liberalne in egalitarne vrednote ter zagovarjajo enake možnosti, do neke mere implicitno pristajajo na spolne stereotipe (Latu idr., 2011) in skozi procese racionalizacije upravičujejo diskriminacijo (Wetherell, Stiven in Potter, 1987). Tudi žrtve diskriminacije, ki sicer priznavajo diskriminacijo na ravni skupine (npr. spolno diskriminacijo v družbi), pogosto ne prepoznajo lastne diskriminiranosti (Crosby, 1984), če pa jo, jo pogosto pripišejo pravilom in ne izvrševalcem diskriminacije, tudi v primeru, ko je očitno, da diskriminacija ne izhaja iz diskriminatornih pravil (Sechrist in Delmar, 2009).

Psihologija prispeva k razumevanju diskriminacije žensk na delovnem mestu prav skozi raziskovanje, na kakšen način in pod kakšnimi pogoji prihaja do diskriminacije ter kateri psihološki mehanizmi diskriminacijo podpirajo in prispevajo $\mathrm{k}$ njeni subtilnosti, razširjenosti in vztrajnosti.

$\mathrm{V}$ tem kratkem pregledu literature najprej obravnavam spolne stereotipe, ki predstavljajo osnovo psiholoških razlag diskriminacije (2. poglavje: Pomen spolnih stereotipov ...) in pojasnim, kako neujemanje med pripisanimi stereotipnimi lastnostmi in zaželenimi lastnostmi na delovnem mestu postane podlaga za diskriminacijo (3. poglavje: Problem zaznane neskladnosti). Sledi razlaga razmeroma subtilnih mehanizmov diskriminiranja žensk na trgu dela (4. poglavje: Standardi ocenjevanja žensk) in mehanizmov upravičevanja in vzdrževanja diskriminacije (5. poglavje: Mehanizmi upravičevanja ...). Na koncu se dotaknem še izsledkov študij, ki poskušajo predvideti, kakšen bo razvoj stereotipov $\mathrm{v}$ prihodnosti (6. poglavje: Pogled v prihodnost).

\section{Pomen spolnih stereotipov pri diskriminaciji žensk na trgu dela}

Pri proučevanju diskriminacije, vključno z diskriminacijo na podlagi spola, se (socialna) psihologija močno opira na stereotipe - pretirano poenostavljena prepričanja o osebnostnih značilnostih posamezne skupine ljudi. Čeprav so stereotipi navadno razmeroma točni (Jussim, Crawford in Rubinstein, 2015), z vidika kognitivnega delovanja človeka precej učinkoviti in ne vedno negativni (Dovidio, Hewstone, Glick in Esses, 2010), je njihovo razumevanje bistvenega pomena za razumevanje diskriminacije. Prvič zato, ker stereotipi omogočajo pripisovanje značilnosti ljudem na osnovi njihove skupinske pripadnosti (t. i. stereotipiziranje) in razvrščanje ljudi v različne socialne skupine (t. i. socialna kategorizacija), drugič pa zato, ker so podlaga za oblikovanje predsodkov (praviloma negativnih stališč do posamezne skupine ljudi oziroma članov skupine), ki se lahko udejanjijo v obliki diskriminacije (neupravičenega negativnega vedenja proti določeni skupini ljudi oziroma njenim članom).

$\mathrm{Ne}$ preseneča torej, da avtorji, ki se ukvarjajo s preučevanjem žensk na trgu dela, spolne stereotipe pogosto navajajo kot ključni vzrok diskriminacije žensk ter vertikalne in horizontalne spolne segregacije trga dela. Spolni stereotipi so prepričanja o tipičnih lastnostih moških in žensk. Te tipične lastnosti dobro opisujeta konstrukta maskulinosti/ agentnosti in femininosti/komunosti. Agentnost je značilnost moškega spolnega stereotipa in odraža temeljno usmerjenost posameznika k sebi, komunost pa karakteristika ženskega spolnega stereotipa in odraža temeljno usmerjenost posameznika k drugim. Agentnost zajema usmerjenost k doseganju, nagnjenost $\mathrm{k}$ prevzemanju vodenja, avtonomijo in racionalnost, komunost pa zajema skrb za druge, težnjo $\mathrm{k}$ pripadnosti in povezovanju, spoštljivost in čustveno občutljivost (Heilman, 2012). Na tem mestu je ključnega pomena razumeti, da sta si agentnost in komunost kot stereotipni skupinski značilnosti pretežno nasprotujoči in dopolnjujoči (bipolarni; Avsec, 2002; Conway in Vartanian, 2000), kot osebnostni (individualni) značilnosti pa sta dve ločeni dimenziji, ki nastopata razmeroma neodvisno druga od druge ${ }^{1}$. Poenostavljeno bi lahko torej rekli, da so ženske tipično komune in ne agentne, moški pa tipično agentni in ne komuni, pri posamezniku pa sta obe dimenziji lahko izraženi visoko, nizko ali pa je ena izražena visoko in druga nizko.

Spolni stereotipi so $\mathrm{v}$ funkciji povečevanja razlik med spoloma in zmanjševanja razlik znotraj spola (povečevanja podobnosti med posamezniki istega spola) ter $\mathrm{v}$ funkciji posploševanja (na vse pripadnike skupine, tudi tiste, ki ne izražajo stereotipnih značilnosti na individualni ravni). Stereotipi opisujejo, kakšni so pripadniki posameznega spola (t. i. opisni stereotipi) in predpisujejo, kakšni bi morali biti (t. i. zapovedni stereotipi) oziroma ne bi smeli biti (t. i. prepovedni stereotipi). Prepovedni stereotipi, vezani na spol, praviloma vključujejo lastnosti drugega spola, ki so prepoznane kot nekompatibilne z zapovednimi stereotipi ${ }^{2}$ (Heilman, 2001). To je z vidika družbenega položaja žensk in njihove možnosti doseganja vodstvenih (delovnih) položajev lahko pomembno, če ženski prepovedni stereotipi zajemajo značilnosti vezane na visok status (npr. dominantnost) in delovno uspešnost (npr. kompetentnost). Komune lastnosti, ki predstavljajo opisne in zapovedne stereotipe za ženske (npr. podpornost), ljudje sicer na splošno ocenjujejo kot bolj pozitivne od agentnih (Eagly in Mladinic, 1989), vendar pa jih obenem povezujejo z nižjim socialnim statusom (Conway in Vartanian, 2000; MossRacusin, Phelan in Rudman, 2010). Poleg tega so ženskam pripisane komune lastnosti nekonsistentne z značilnostmi, ki jih povezujemo $z$ delovno uspešnostjo, še posebej na bolj zahtevnih in višjih delovnih mestih (Heilman in Eagly, 2008). Povedano drugače, čeprav ljudje prav zaradi stereotipa komunosti ženske v splošnem ocenjujejo celo bolj pozitivno kot moške, te pripisane pozitivne lastnosti ženske postavljajo 
primarno $\mathrm{v}$ sfero družine in ne $\mathrm{v}$ sfero produktivnega dela (Eagly in Mladinic, 1994; Eagly in Steffen, 1984).

Na tem mestu velja izpostaviti, da ni nujno, da so stereotipi negativni, da bi na podlagi njih prišlo do predsodkov in diskriminacije, zadostuje namreč, da opazovalci zaznajo neskladnost med pripisanimi (stereotipnimi) lastnostmi in zahtevami posamezne socialne vloge oziroma (delovne) naloge (Heilman in Eagly, 2008).

\section{Problem zaznane neskladnosti}

Omenjen problem zaznane neskladnosti obravnavata teorija neskladnosti vlog (Eagly in Karau, 2002) in model pomanjkanja ujemanja (Heilman, 1983). Teorija neskladnosti vlog se prvenstveno osredotoča na predsodke do žensk vodij, medtem ko je model pomanjkanja ujemanja nekoliko širši in obravnava različna spolno-tipska delovna mesta (med njimi tudi vodstvene položaje). Obe teoriji poudarjata, da prav zaznana neskladnost prispeva k oblikovanju negativnih pričakovanj uspešnosti in vpliva na izkrivljeno procesiranje informacij (npr. procese pozornosti, atribucije, interpretacije in priklica informacij) (glej Heilman, 2012), preko tega pa na dejanske posledice za ženske na trgu dela.

Diskriminacija po mnenju Eagly in Karau (2002) ter Heilman (1983) ne izvira iz spola samega po sebi, temveč iz zaznanega neujemanja med (stereotipnimi) značilnostmi žensk in zahtevami delovnega mesta (Heilman in Eagly, 2008). Povedano drugače, problem je v tem, da ženskam pripisane in predpisane (pozitivne) značilnosti niso skladne s konceptom idealnega delavca (Kelly, Ammons, Chermack in Moen, 2010) in z večino vplivnejših delovnih položajev (Heilman in Eagly, 2008). Še več, če drži, da so lastnosti, ki so zaznane kot pomembne za uspešnost na delovnem področju, zajete $\mathrm{v}$ prepovedni stereotip, bo njegovo kršenje prineslo socialne sankcije.

Večje kot je zaznano neujemanje med značilnostmi osebe in zahtevami delovne naloge, bolj negativno je pričakovanje uspešnosti in bolj pristranska je ocena osebe $\mathrm{v}$ procesu novačenja, izbora, ocenjevanja in napredovanja kandidatov na delovnem mestu. $K$ velikosti zaznanega neujemanja pa prispevajo dejavniki, vezani na značilnost delovnega mesta oziroma okolja (spolna-tipskost) in značilnosti osebe, vezane na spol (Heilman in Parks-Stamm, 2007).

\section{Spolna-tipskost delovnega mesta}

Spolno-tipskost delovnega mesta ne opredeljujejo le delovne naloge, ampak tudi organizacijska dejavnost/sektor (npr. vojska kot moško-tipska nasproti izobraževanju kot žensko-tipski dejavnosti), podpodročje oziroma specialistično področje dejavnosti (npr. finančni menedžment nasproti kadrovskemu menedžmentu), akademsko področje (npr. naravoslovje nasproti humanistiki) ter funkcija oziroma nivo položaja znotraj organizacije (npr. višji nasproti nižjemu menedžmentu). Spolna-tipskost je načeloma funkcija spolne strukture organizacije, sektorja oziroma posameznih (pod)področij. Za spolno-tipska delovna mesta ljudje verjamejo, da zaposleni potrebuje značilnosti, ki so kategorizirane kot maskuline/agentne (moška-tipskost) oziroma kot feminine/komune (ženska-tipskost).
Večja je zaznana neskladnost med osebo in delovnim mestom, večje je pričakovanje, da oseba nima sposobnosti, da bi bila uspešna na delovnem mestu. V samem procesu zaposlovanja se bo odločevalec zato raje odločil, da zaposli osebo, ki se stereotipno ujema $\mathrm{z}$ delovnim mestom.

Ker se je večina raziskav na področju zaznane neskladnosti osredotočala na vodstvena delovna mesta, se to odraža tudi v pričujočem pregledu literature. Za vodstvena delovna mesta velja, da so skoraj vedno moško-tipska (Koenig, Eagly, Mitchell in Ristikari, 2011), saj naj bi zahtevala agresivno usmerjenost k dosežkom in emocionalno čvrstost - lastnosti, tipično pripisani moškim (Heilman, 2001). Moška-tipskost vodstvenih položajev predstavlja oviro za ženske. Na ravni kadrovanja se to kaže v procesu novačenja in izbora kadrov ženske so v primerjavi z moškimi redkeje zaposlene direktno na njih (Elsesser in Lever, 2011), saj je ob pomanjkanju dodatnih informacij o posameznici zanašanje na stereotipe večje. Ženske tako do vodstvenih položajev pogosteje pridejo z napredovanjem (Elsesser in Lever, 2011), ko dodatne informacije o posameznici delno nadomestijo ali reducirajo spolne stereotipe v procesu odločanja (t. i. hipoteza stika). Vendar pa tudi v primeru zaposlitve na moško-tipsko delovno mesto ne uidejo diskriminaciji, saj so prav na teh delovnih mestih najpogosteje žrtve sovražnosti in diskriminacije (Riach in Rich, 2002; Bobbit-Zeher, 2011), ki nastopajo kot sankcije za izneverjenje predpisani spolni vlogi ter prevzemanje vlog (položajev) drugega spola.

Stereotipi so razmeroma odporni na spremembe tudi preko kognitivnih mehanizmov pristranske pozornosti (Allen, Sherman, Conrey in Stroessner, 2009) in procesov razlaganja s stereotipi neskladnega vedenja (Sherman, Stroessner, Conrey in Azam, 2005), zaradi česar je napredovanje žensk $\mathrm{v}$ primerjavi z moškimi oteženo tudi $\mathrm{v}$ primeru, ko se na delovnem mestu izkažejo. Poleg tega uspešne ženske, ki so zaznane kot agentne, kršijo zapovedne in prepovedne stereotipe, zaradi česar utrpijo negativne ekonomske in socialne posledice (Heilman, Wallen, Fuchs in Tamkins, 2004; Rudman in Phelan, 2008).

\section{Značilnosti osebe, vezane na zaznano agentnost oziroma komunost}

Ne samo delovna mesta, tudi posamezniki so lahko zaznani kot bolj ali manj stereotipno maskulini oziroma feminini. Pri ženskah določeni osebni atributi, kot na primer materinstvo, nosečnost in privlačen fizični videz, ojačajo pripisovanje femininih/komunih lastnosti, s tem pa vplivajo na ocenjevanje žensk na delovnem mestu (Benard, Paik in Correl, 2008; Heilman, 2012; Heilman in Stopeck, 1985).

Raziskovalci (Benard in Correll, 2010; Benard idr., 2008; Fuegen, Biernat, Haines in Deaux, 2004) so eksperimentalno večkrat pokazali, da ocenjevalci matere ocenjujejo kot manj kompetentne in pripadne ter primerne za zaposlitev, izobraževanje in napredovanje na delovnem mestu $v$ primerjavi z enako kompetentnimi ženskami, ki niso matere, in $\mathrm{v}$ primerjavi $\mathrm{z}$ očeti ${ }^{3}$. Razkorak, ki ga utrpijo matere, gre pripisati poudarjenemu stereotipu komunosti, pa tudi pričakovanjem, da ne bodo mogle zadostiti normi idealnega delavca, tj. zaposlenega, ki je vedno na razpolago (Kelly idr., 2010). V primeru, da tej normi zadostijo, zbudijo sum kršitve 
norme intenzivnega materinstva (Hays, 1996; Johnston in Swanson, 2006), ki predpisuje, da (dobra) mati vlaga čezmerno veliko časa in virov v svoje otroke, kar seveda pomeni primanjkljaj časa in virov za vlaganje v plačano delo. Podobno velja za noseče ženske. Tudi te so $\mathrm{v}$ primerjavi z enako kompetentnimi ženskami, ki niso noseče, zaznane kot manj zaposljive, manj delovno uspešne in predane delu (Halpret, Wilson in Hickman, 1993).

Načeloma velja, da imajo fizično privlačne osebe prednost na vrsti zaposlitvenih izidov ${ }^{4}$ (Hosoda, Stone-Romero in Coats, 2003), vendar pa na drugi strani raziskovalci ugotavljajo, da poudarjanje fizične privlačnosti pri ženskah in pritegnitev pozornosti ocenjevalcev na videz kandidatke oz. zaposlene, negativno vpliva na oceno njene kompetentnosti in inteligentnosti, pa tudi na čustveno doživljanje te osebe (Glick, Larsen, Johnson in Branstiter, 2005; Heflick, Goldenberg, Cooper in Puvia, 2011; Heilman in Stopeck, 1985), še posebej, če gre za kandidatko oz. zaposleno na višjem položaju (Heilman, 1983; Heilman in Stopeck, 1985). Všečen fizični videz je torej lahko prednost, vendar le za delovna mesta, kjer stereotipi komunosti ne predstavljajo ovire, na primer skrbstvene in storitvene poklice nižje in srednje ravni.

\section{Standardi ocenjevanja žensk}

\section{Pristransko ocenjevanje žensk}

V šestdesetih letih prejšnjega stoletja je Goldberg (1968) oblikoval enostaven eksperiment, v katerem so študentke ocenile šest različnih člankov z različnih področij. Polovica študentk je prejela članek podpisan $\mathrm{z}$ moškim imenom, polovica pa z ženskim. Trije članki (oba z moško-tipskega področja in en s spolno nevtralnega področja) so bili ocenjeni slabše v pogoju, ko je bila podpisana ženska. Goldbergovemu paradigmatskemu eksperimentu je sledila vrsta eksperimentov z različnimi dražljaji in skupinami udeležencev. Metaanaliza (Swim, Borgia, Maruyama in Myers, 1989) več kot sto tovrstnih eksperimentov je pokazala, da so v splošnem razlike med ocenami moških in žensk zanemarljivo majhne, vendar pa je ob bolj natančnem pregledu očitno, da raziskave, ki uporabljajo dražljaje, vezane na moško-tipska ali spolno nevtralna področja, ugotavljajo opazno pristranskost do žensk. Podobno je pokazala metaanaliza eksperimentov Goldbergovega tipa s področja vodenja in menedžmenta (Eagly, Makhijani in Klonsky, 1992). Razlike so bile na splošno zanemarljive, vendar pa so bile večje v primerih, ko so bili ocenjevalci moški, področje moško-tipsko, stil vodenja ženske pa »maskulin«. Navedene ugotovitve so se ponovno potrdile v metaanalizi, opravljeni dobri dve desetletji kasneje (Koch, D’Mello in Sackett, 2015). Ti izsledki so razmeroma skladni s teorijama s področja zaznane neskladnosti, je pa zanimiva ugotovitev raziskav Goldbergovega tipa predvsem ta, da ženske nimajo prednosti pred moškimi na ženskotipskih nalogah, kakor bi lahko pričakovali po teoriji neskladnosti vlog in modelu pomanjkanja ujemanja, ter da ženske $\mathrm{v}$ enaki meri kot moški slabše ocenjujejo ženske na moško-tipskih nalogah, medtem ko moških ne ocenjujejo kot slabše na žensko-tipskih in spolno nevtralnih nalogah.

\section{Dvojni in pomični standardi}

Eksperimenti Goldbergove paradigme so predvsem poskusi ugotavljanja prisotnosti diskriminacije žensk (Goldberg je razlike v ocenah pripisal predoskom), ne razkrijejo pa veliko o tem, na kakšen način in na podlagi česa posamezniki pridejo do (različnih) ocen žensk in moških.

Zakaj enako kvalitetni izdelki moških in žensk niso vedno ocenjeni enako, poskušata razložiti teorija dvojnih standardov (Foschi, 1989, 1998) in model pomičnih standardov (Biernat, 1995). Standardi predstavljajo norme oziroma zahtevane ravni uspešnosti, da lahko sprejmemo sklep o prisotnosti (odsotnosti) določene lastnosti, npr. kompetnentosti, moralnosti ipd. Teorija dvojnih (tudi multiplih) standardov predpostavlja, da so standardi različni za osebe, ki jim je pripisan visok status, in osebe, ki jim je pripisan nizek družben status, in sicer zato, ker so pričakovanja za ti skupini različna. Ocenjevalci standarde, ki jih uporabljajo za ocenjevanje, prilagajajo na tak način, da potrdijo svoja pričakovanja. Dvojni standardi so torej mehanizem ohranjanja statusa quo, saj omogočajo ocenjevanje skupin nižjega statusa na način, ki potrjuje in opravičuje njihov družben položaj. Tipično to pomeni višje oziroma strožje standarde za osebe nižjega statusa in zmanjševanje pomembnosti dosežkov oseb nižjega statusa (Foschi, 2006). To potrjujejo tudi eksperimentalne študije (pregled v Foschi, 2000), ki ugotavljajo, da so ženske izpostavljene višjim standardom, še posebej v primeru, ko jih ocenjujejo moški ali pa da ocenjevalci neposredno primerjajo dva kandidata različnih spolov. Še več, raziskave kažejo tudi, da ženske same sebi postavljajo višje standarde na moškotipskih in spolno nevtralnih nalogah.

Raziskovanje dvojnih standardov sta Lyness in Heilman (2006) prenesli v naravno okolje. S pregledom dokumentacije o ocenah delovne uspešnosti in napredovanja žensk in moških na vodstvenih položajih sta ugotovili, da so v primerjavi z moškimi ženske morale imeti precej višje ocene uspešnosti, da so dosegle napredovanje. Ocene uspešnosti žensk so se tudi $\mathrm{v}$ večji meri povezovale $\mathrm{z}$ njihovim napredovanjem, kar kaže ne le na višje standarde, ampak tudi bolj stroge/toge standarde napredovanja za ženske.

Če teorija dvojnih standardov govori o statusu oseb $\mathrm{ki}$ je odvisen od statusnih karakteristik, npr. spola, etničnosti, socialno-ekonomskega statusa, model pomičnih standardov govori o pripadnosti različnim socialnim skupinam, za katere veljajo različni stereotipi. Po modelu premičnih standardov ocenjevalci, če je to le mogoče (npr. če je ocenjevanje delno ali v celoti subjektivno) uporabljajo različne standarde za različne socialne skupine ocenjevancev glede na pripisane stereotipne značilnosti. Standardi so dveh vrst - minimalni standardi in potrditveni standardi (ti so analogni standardom, o katerih govori teorija dvojnih standardov). Pri socialnih skupinah, kjer stereotipi implicirajo nižjo izraženost neke značilnosti, bodo minimalni standardi navadno nižji, medtem ko bodo potrditveni standardi (tj. meja potrditve, da posameznik le ima določeno lastnost) višji. Pojasnjeno na primeru kompetentnosti: ženske so stereotipno pojmovane kot manj kompetentne od moških, zato bo njihova kompetentnost zaznana hitreje kot pri moških (minimalni standard je nižji oz. ženska je hitreje zaznana kot »sposobna za žensko«), 
medtem ko bodo ocenjevalci potrebovali precej več dokazov o njeni uspešnosti kot pri moških, preden bodo zaključili, da je kompetentna (potrditveni standard je višji). Enako velja za moške - ker je nekompetentnost moških nepričakovana, jo bodo ocenjevalci opazili hitreje, vendar pa bodo potrebovali precej več potrditev, preden bodo moškega označili za nekompetentnega (Biernat, Fuegen in Kobrynowicz, 2010).

Konkretno, na podlagi pregleda 81 parov formalnih in neformalnih zapiskov o vedenju zaposlenih so raziskovalci (Biernat idr., 2010) ugotovili, da so ocenjevalci za beleženje negativnih vedenj moških (na položaju menedžerja) $v$ večji meri uporabljali neformalne zapiske, katerih funkcija je predvsem podajanje povratne informacije zaposlenemu, kakor formalne obrazce, katerih funkcija je odločanje o napredovanju in finančnemu nagrajevanju zaposlenega. Primerjalno so ocenjevalci negativna vedenja žensk v bistveno večji meri vključevali $\mathrm{v}$ formalne obrazce, ki imajo večjo težo pri odločanju o zaposlenem, in $\mathrm{v}$ manjši meri $\mathrm{v}$ neformalne zapiske. Neuspešnost moških torej ni neopažena, je pa $\mathrm{v}$ manjši meri upoštevana pri odločanju o njihovih karierah.

Čeprav obe teoriji razlagata diskriminatorno rabo standardov, ki prispevajo k ohranjanju družbenih razlik med spoloma, se v svojih napovedih malenkost razlikujeta. Prvič, teorija dvojnih standardov predpostavlja, da bodo dokazi o kompetentnosti ženske odpravljeni kot manj pomembni, model pomičnih standardov pa predpostavlja, da bo ženska hitreje prepoznana kot kompetentna - kompetentna za žensko. Drugič, teorija dvojnih standardov predpostavlja, da so standardi za ženske (v primerjavi z moškimi) višji ne glede na nalogo, model pomičnih standardov pa predpostavlja višje standarde le pri moško-tipskih nalogah (zaradi stereotipne neskladnosti).

Glede na dosedanje izsledke bi lahko trdili, da teorija dvojnih standardov (Foschi, 1989, 1998) bolje razlaga proces diskriminacije žensk. S tem, ko družben položaj skupine (sicer vezan na spol) razume kot pomembnejši napovednik diskriminatornega ocenjevanja od spolnih stereotipov samih po sebi, bolje razloži izsledke študij Goldbergovega tipa in vrste drugih študij, ki kažejo, da ženske nimajo prednosti pred moškimi na žensko-tipskih delovnih mestih ${ }^{5}$. To nikakor ne implicira nepomembnosti spolne-tipskosti (moški, na primer, na žensko-tipskih delovnih nalogah niso ocenjeni boljše od žensk), vendar pa kaže na interakcijo med pripisanim družbenim statusom in spolnimi stereotipi.

\section{Različna pričakovanja - različni kriteriji}

Ne le da so standardi različno visoki za ženske in moške, so tudi vsebinsko drugačni. Ocenjevalci namreč uporabljajo vsebinsko različne kriterije glede na spol ocenjevanca. $\mathrm{Na}$ primer, v eksperimentu so raziskovalci (Heilman in Chen, 2005) pokazali, da altruistično vedenje na delovnem mestu pozitivno vpliva na ocene in napredovanje moških, ne vpliva pa na oceno in napredovanje žensk, še več, v primeru, ko se ženske niso vedle altruistično, so bile kaznovane $\mathrm{z}$ nižjo oceno in manjšimi možnosti napredovanja. Povedano drugače, altruistično (komuno) vedenje je za ženske obvezno (se od njih pričakuje), medtem ko je za moške izbirno.
Od žensk na vodstvenih položajih podrejeni v večji meri pričakujejopodpornost, skrbnost, osebnipristop,razumevanje, empatičnost, sposobnost prisluhniti drugemu, pa tudi posluh za usklajevanje dela $\mathrm{z}$ družinskimi obveznostmi, kompetence organiziranja in komuniciranja (Elsesser in Lever, 2011), če pri tem spodletijo, pa tvegajo nepriljubljenost in slabše zaposlitvene možnosti (Heilman in Wallen, 2010).

$Z$ vidika zaznane (ne)skladnosti mora ženska na moško-tipskem delovnem mestu prevzeti pozitivna spolno nekonsistentna agentna vedenja, ki so skladna $\mathrm{z}$ njeno delovno vlogo, in hkrati dovolj jasno izkazovati pozitivna spolno konsistentna vedenja, skladna $\mathrm{z}$ njeno spolno vlogo. Agentnost je na primer ključna za prepoznanje kompetentnosti vodje (Heilman, 2001; Heilman in Okimoto, 2007; Johnson, Murphy, Zewdie in Reichard, 2008), komunost pa za izognitev negativnim socialnim ocenam in posledicam na nadaljnje karierne možnosti (Heilman, 2001; Phelan, MossRacusin in Rudman, 2008). Pričakovanja o stilu vodenja se torej razlikujejo glede na spol (Garcia-Retamero in LopezZafra, 2009; Johnson idr., 2008); če za moške zadostuje, da so agentni, morajo ženske agentnost ${ }^{6}$ kombinirati tudi s komunostjo.

\section{Mehanizmi upravičevanja in vzdrževanja diskriminacije žensk na trgu dela}

\section{Atribucije uspešnosti}

Izraz atribucija se nanaša na način (vsebino) razlaganja vedenja drugih. Atribucije delimo na notranje atribucije, ki označujejo pojasnjevanje vedenja $\mathrm{z}$ osebnimi lastnostmi akterja, in zunanje atribucije, ki označujejo razlaganje vedenja akterja s situacijskimi dejavniki. Na atribucije pomembno vplivajo stereotipi, in sicer tako, da ljudje vedenja, ki so konsistentna s stereotipi, pripisujejo razmeroma stabilnim osebnostnim lastnostim, medtem ko s stereotipi nekonsistentna vedenja pripisujejo značilnostim situacije (Jackson, Sullivan in Hodge, 1993). Tisti, ki so v večji meri prepričani $\mathrm{v}$ točnost stereotipov, uporabljajo te atribucijske vzorce bolj konsistentno (Cundiff in Vescio, 2016). To je z vidika diskriminacije žensk na trgu dela zelo pomembno spoznanje, saj vsebine spolnih stereotipov služijo kot podpora ohranjanju hierarhije med spoloma preko atribucij, ki delujejo kot subtilen mehanizem racionalizacije in upravičevanja spolne hierarhije v družbi.

Skladno s stereotipi o uspešnosti moških in neuspešnosti žensk na moško-tipskih nalogah, tudi raziskave, ki so preučevale atribucije, ugotavljajo, da uspeh moških na moško-tipskih nalogah ocenjevalci pripisujejo spretnostim, kompetentnosti, inteligentnosti (tj. notranje atribucije), uspeh žensk na teh nalogah pa v večji meri razlagajo kot posledico zunanjih dejavnikov (Cundiff in Vescio, 2016; Deaux in Emswiller, 1974; Garcia-Retamero in Lopez-Zafra, 2009), kar sovpada s teorijo neskladnosti vlog in modelom pomanjkanja ujemanja. Vendar pa nekatere raziskave (Garcia-Retamero in Lopez-Zafra, 2009) kažejo, da ta vzorec atribuiranja presega moško-tipske delovne naloge (čeprav je pri njih najbolj izrazit) in ugotavljajo, da ocenjevalci na splošno v večji meri 
uporabljajo zunanje atribucije za razlago uspešnosti žensk kot moških. Poleg tega pri moških ocenjevalci v večji meri uporabljajo notranje atribucije tudi za razlago uspehov na žensko-tipskih nalogah. Vprašanje je, v kakšni meri uspeh sam po sebi sovpada s stereotipom agentnosti ne glede na spolno-tipskost naloge oziroma je atribuiranje pod vplivom zaznanega družbenega statusa, kot je predlagala Foschi (1989, 1998). Kljub temu pa lahko povzamemo, da težnja k pripisovanju uspešnosti moškim zaradi njihovih sposobnosti, uspešnosti žensk pa (tudi) zaradi sreče, predstavlja oviro za ženske na področju zaposlovanja in napredovanja, še posebej na višjih in moško-tipskih delovnih mestih, saj izbor ženske v očeh delodajalca prinaša večje tveganje glede uspešnosti.

\section{Identifikacija in pomanjkanje identifikacije z lastno skupino}

Načeloma velja, da ljudje (pre)visoko vrednotimo lastno skupino in (pre)nizko druge skupine, saj pozitivno ovrednotenje lastne skupine zvišuje našo samopodobo (pregled v Aberson, Healy in Romero, 2000). Ta pozitivna pristranskost do lastne skupine in negativna do drugih je praviloma osnova skupinske diskriminacije. Če to prenesemo na področje spola, ne preseneča, da imajo moški bolj maskulin konstrukt vodenja kot ženske (Koenig idr., 2011; Latu idr., 2011) in bolj pogosto zaznavajo ženske kot manj kvalificirane za vodstvene položaje (Schein, 2001) ter da bolj negativno pristrano ocenjujejo ženske, kot ženske ocenjujejo druge ženske (Koch idr., 2015). Prav tako v večji meri zanikajo diskriminacijo na podlagi spola in družbene razlike med spoloma večkrat pripisujejo dispozicijam kot socializacijskim dejavnikom (Cundiff in Vescio, 2016). Moški imajo namreč očitno korist $v$ vzdrževanju obstoječe spolne hierarhije, ki je njim v prid. Manj jasno pa je, zakaj večina študij spolnih stereotipov ne poroča o pomembnih razlikah med moškimi in ženskami pri ocenjevanju moških in žensk - zakaj torej ženske ne vrednotijo enako visoko ali celo višje drugih žensk in nižje moških niti na žensko-tipskih niti na moško-tipskih nalogah.

Avtorji so to poskušali pojasniti predvsem na dva načina. Prvi je ta, da so tudi ženske podvržene in v veliki meri sprejemajo spolne stereotipe, drugi pa je posledica socialne primerjave oziroma tekmovalnosti med ženskami (Elsesser in Lever, 2011; Heilman, 2012). Uspešne ženske, predvsem na moško-tipskih delovnih mestih, ki jim je običajno pripisan višji status, predstavljajo za ocenjevalke visok standard socialne primerjave in tako ogrožajo njihovo samopodobo. Rešitev te napetosti se zgodi skozi rabo predpisnih stereotipov, ki predstavljajo orodje za sankcioniranje uspešnih žensk skozi negativno socialno oceno (Parks-Stamm idr., 2008). ParksStamm je s sodelavkama (2008) eksperimentalno pokazala, da uspeh posameznice na vodstvenem položaju negativno vpliva na občutek lastne kompetentnosti drugih žensk. Možnost negativne socialne ocene uspešne ženske s strani opazovalk pa uspešno ublaži ta občutek ${ }^{7}$. Ključno vprašanje, preden lahko naredimo kakršne koli zaključke, je, ali lahko pokažemo ta isti proces (negativne socialne primerjave) med moškimi. Nobenega razloga namreč ni, da bi predpostavili, da ženske v večji meri tekmujejo med sabo kot moški (Cashdan,
1998), pa čeprav raziskovalci preučujejo praktično izključno tekmovalnost med ženskami (Mavin in Williams, 2013) ali med spoloma (Niederle in Vesterlund, 2011).

\section{Pogled v prihodnost}

\section{Sprememba stereotipov}

Stereotipi so dinamični, kar pomeni, da se skupaj z družbenimi spremembami vsebinsko spreminjajo tudi stereotipi o družbenih skupinah. Kot sem izpostavila na začetku prispevka, so stereotipi resda pretirano posplošena stališča, vendar pa tudi mnogokrat razmeroma točna refleksija dejanskih razlik, delitve dela, segregacije na trgu dela in družbene hierarhije (Eagly, Wood in Diekman, 2000), zato ni presenetljivo, da vsebine spolnih stereotipov odražajo spremembe (produktivnih in reproduktivnih) socialnih vlog v družbi. Wilde in Diekman (2005) sta v svoji raziskavi dinamičnih spolnih stereotipov preteklosti (leta 1950), sedanjosti (leta 2005) in prihodnosti (leta 2050) ugotovili hitrejše spreminjanje stereotipov (tipičnih pripisanih lastnosti) žensk kakor moških. Pri ženskah opazimo porast v pripisanih maskulinih osebnostnih lastnostih ter miselnih in fizičnih značilnostih, medtem ko so feminine značilnosti ostale relativno stabilne (enako značilne). To odraža intenzivno vključevanje žensk na trg dela (ne glede na zakonski in materinski status), hkrati pa še vedno prevladujočo prevzemanje skrbstvenih vlog v družbi. Nasprotno se moški niso $\mathrm{v}$ takšni meri integrirali $\mathrm{v}$ dejavnosti, ki so stereotipno ženske (npr. skrbstveno in gospodinjsko delo). V prihodnje ljudje pričakujejo nadaljevanje trenda naraščanja maskulinih značilnosti pri ženskah, medtem ko stereotipi maskulinosti ostajajo manj dinamični. Spolni stereotipi odražajo tudi druge družbene spremembe, npr. pri obeh spolih je predviden porast negativne maskulinosti (egoizma, bahaštva, agresivnosti, pohlepnosti, arogantnosti ...), kar najverjetneje odraža povečano individualizacijo družb in naraščanje tekmovalnosti na trgu dela. Predviden je tudi večji poudarek tako na »ženskih« (npr. ustvarjalnosti) kot »moških« (npr. analitičnosti) kognitivnih značilnosti, najverjetneje kot posledica tehnološkega razvoja in vedno večjih zahtev po ustvarjalnosti in inovativnosti (Wilde in Diekman, 2005). Te ugotovitve so bile replicirane (Lopez-Zafra in GarciaRetamero, 2012) z dodano ugotovitvijo, da starejši stereotipe doživljajo bolj dinamično kot mlajši, kar ne preseneča, saj so v svojem življenjskem obdobju bili priča večjim družbenim spremembam na področju emancipacije žensk.

\section{Novi pogledi na zahteve dela}

Tudi na področju razumevanja zahtev različnih delovnih mest, ki so tradicionalno spolno-tipska, prihaja do sprememb v času. Čeprav še vedno velja, da je stereotipna predstava vodje skladna s stereotipom maskulinosti, se ta predstava nekoliko rahlja (Koenig idr., 2011). Slednje se ne dogaja le zaradi večje emancipacije in participacije žensk, temveč tudi zaradi spremembe delovnih okolij, še posebej menedžerskih delovnih položajev, ki zaradi socialnih in tehnoloških 
sprememb ter povečane kompleksnosti zahtevajo premik $\mathrm{k}$ bolj demokratičnim načinom vodenja, participativnem odločanju, delegaciji in vodenju moštev, ki v veliki meri temeljijo na usmerjenosti k drugemu (komunosti) (Koenig idr., 2011). V splošnem je sicer predstava o dobri vodji še vedno nasičena $\mathrm{z}$ agentnimi značilnosti, vendar pa postopoma pridobiva elemente komunosti. Sodoben, pogosto priporočen in učinkovit stil vodenja, t. i. transformacijsko vodenje, temelji na interakciji med vodjo in podrejenimi, v kateri vodja navdihuje in spodbuja podrejene za doseganje skupinskih ciljev. Tako vodenje vključuje vedenja upoštevanja in podpore podrejenim, intelektualno stimulacijo in komuniciranje smisla in pomena dela, ki jih ljudje $\mathrm{v}$ večji meri pripisujejo ženskam kot moškim (Vinkenburg, Van Engen, Eagly in Johannsen-Schmidt, 2011). Prav v večjem sovpadanju s komunimi značilnostmi se razlikuje od drugih stilov vodenja (npr. transakcijskim vodenjem in laisse-faire vodenjem), ki so manj učinkoviti. Je pa treba poudariti, da tudi transformacijsko vodenje še vedno močno sovpada $\mathrm{Z}$ agentnimi lastnostmi (npr. usmerjenost k ciljem, ambicioznost in samozavest) (Vinkenburg idr., 2011; Kark, Waismel-Manor in Shamir, 2012), vendar pa najverjetneje nasičenje koncepta učinkovitega vodenja s komunimi značilnostmi še ne zadošča za odpravitev diskriminacije žensk na vodstvenih položajih. Te so, kakor sem pokazala, tarča različnih mehanizmov diskriminacije, vključno $\mathrm{z}$ višjimi standardi in različnimi pričakovanji ter zahtevnega usklajevanja vedenj komunosti in agentnosti, ki presegajo okvire opisanih delovnih nalog in delovnih zahtev.

\section{Sklep}

Pričujoči prispevek obravnava pervazivnost spolnih stereotipov in njihovo ključno vlogo pri diskriminaciji žensk na trgu dela. Spolni stereotipi pomembno zaznamujejo zaznavanje žensk in moških, vplivajo na pričakovanja o osebnostnih lastnostih in vedenjih ter na pojasnjevanje vedenj posameznikov in pripomorejo $\mathrm{k}$ upravičevanju obstoječih družbenih razmerij med spoloma.

Socialna psihologija se že več kot pol stoletja aktivno ukvarja s preučevanjem diskriminacije žensk na trgu dela, pa vendar nekatera področja ostajajo neraziskana, druga nerazjasnjena, tretja pa so močno odvisna od različnih družbenih sprememb, zaradi česar mora biti raziskovanje stereotipov in diskriminacije $\mathrm{v}$ psihologiji kontinuirano. Odprto ostaja vprašanje, kateri spolni stereotipi so zapovedni in kateri prepovedni, ter $\mathrm{v}$ kakšni meri se prekrivajo $\mathrm{s}$ spolnimi stereotipi nasprotnega spola. Še vedno ni povsem jasno, ali so ženske motivirane za negativno ocenjevanje drugih žensk, ali je to predvsem odraz prevzemanja kulturno in družbeno posredovanih stereotipov in predsodkov. Obstaja tudi velika vrzel pri proučevanju nižjih in manj prestižnih delovnih mest.

Področje žensko-tipskih delovnih mest odkriva tudi nekatere šibke točke teorij, ki se opirajo na skladnost spolnih stereotipov. Zdi se namreč, da skladnost med delovnim mestom in spolnimi stereotipi ne prinaša prednosti ženskam, prinaša pa prednost moškim. Razlogi za takšne ugotovitve so lahko v izbiri preučevanih delovnih mest, ki so bila praviloma višje ravni, ali pa v pripisovanju boljših (splošnih) sposobnosti moškim ne glede na področje dela. Predpostavljam, da je odgovor na to vezan tako na spolno-tipskost kakor tudi na prestiž delovnega mesta, in sicer manj prestižna ženskotipska delovna mesta (npr. vzgojitelj/ica v vrtcu ali kadrovik/ ica) ostajajo rezervirana za ženske, bolj prestižna pa zaradi višjega pripisanega statusa (asociiranega $\mathrm{z}$ moškimi) V praksi delujejo kot spolno nevtralna (npr. ravnatelj/ica ali kadrovski/ska menedžer/ka). Z nadaljnjim pridobivanjem na statusu pa celo kot moško-tipska (npr. predsednik/ica združenja ravnateljev ali predsednik/ica uprave), kar pomeni oviro pri vertikalni mobilnosti žensk. Premalo raziskane so tudi ovire pri vstopanju žensk na nižje in srednje vrednotena moško-tipska delovna mesta $\mathrm{z}$ vidika izbire in napredovanja zaposlenih, ne le psihološkega delovanja (uspešnih) žensk na teh delovnih mestih (Derks, Van Laar in Ellemers, 2016).

Psihološke raziskave odkrivajo, kako subtilni mehanizmi diskriminacije žensk na trgu dela, ki v večji meri izhajajo iz spolnih stereotipov, ovirajo uveljavljanje žensk z mehanizmi podcenjevanja njihovih dosežkov (zunanje atribucije), postavljanja višjih zahtev (dvojni, pomični in dodatni standardi), negativne selekcije glede na skladnost delovnega mesta s spolnimi stereotipi (neskladnost vlog oziroma pomanjkanje ujemanja) in dvoma $\mathrm{v}$ dolgoročno smotrnost zaposlitve (norma idealnega delavca). Poskušajo pa ponuditi tudi konkretne rešitve za zmanjšanje pristranskosti proti ženskam na (i) organizacijski ravni, npr. s postavljanjem jasnih kriterijev uspešnosti in dobro strukturiranimi procesi ocenjevanja, še posebej pri timskem delu (Heilman in Haynes, 2005; Heilman, 2001), ter organizacijskih vrednot oz. norm enakosti (Koch idr., 2015); (ii) na ravni ocenjevalcev zaposlenih, npr. soodvisnost (Fiske, 2000) in odgovornost ocenjevalca (Koch idr., 2015); (iii) ter na ravni zaposlenih ${ }^{8}$, npr. združevanje agentnosti s komunostjo (Johnson idr., 2008). Čeprav te intervencije same po sebi ne presegajo ravni posameznika in organizacije, to še ne pomeni, da z družbenega vidika spoznanja psihologije o diskriminaciji žensk niso bistvena. Prav nasprotno, s tem ko psihologija odgovarja na vprašanja, izpostavljena $\mathrm{v}$ uvodu (na kakšen način in pod kakšnimi pogoji prihaja do diskriminacije ter kateri mehanizmi otežujejo njeno odpravljanje), ključno prispeva $\mathrm{k}$ razumevanju in spreminjanju družbene stvarnosti.

\section{Končne opombe}

${ }^{1} \mathrm{~V}$ prvih opredelitvah maskulinosti/agentnosti in femininosti/ komunosti, sta bila ta dva konstrukta predstavljena kot enodimenzionalna, se pravi izključujoča se, kasneje pa se je na podlagi empiričnih podatkov in teoretskih kritik uveljavilo večdimenzionalno merjenje agentnosti in komunosti, kar pomeni, da na agentnost in komunost ne gledamo več kot na izključujoča se konstrukta, temveč kot dimenziji, ki se pri posamezniku pojavljata skupaj v kakršni koli izraženosti (pregled v Lippa, 2001).

\footnotetext{
${ }^{2}$ Heilman gre tukaj še nekoliko dlje, in sicer pravi, da prepovedni stereotipi za ženske (mnogokrat) vključujejo tudi tiste agentne značilnosti, ki so cenjene pri moških (glej: Heilman, 2001, str. 659). To ne sovpada povsem z empiričnimi ugotovitvami, ki jih predstavljam v nadaljevanju (glej poglavje 4.3). Pravzaprav glede na dosedanje raziskave (npr. Parks-Stamm, Heilman in Hearns, 2008) prepovedni stereotip za ženske bolj verjetno vključuje
} 
značilnosti, ki so prepoznane kot antikomune (npr. zajedljivost, vsiljivost, strogost, neobčutljivost, neprijaznost, hladnost, sebičnost, manipulativnost) in ne nujno kot agentne. Odprto vprašanje pa je, $v$ kakšni meri so agentne lastnosti, pripisane ženskam, interpretirane kot antikomune (npr. asertivnost kot agresivnost, odločnost kot neprilagodljivost, zasledovanje lastnih ciljev kot sebičnost ipd.).

${ }^{3}$ Očetovstvo na drugi strani moškim prinaša celo prednost. Očete $\mathrm{v}$ primerjavi z neočeti ocenjevalci zaznavajo kot bolj prijazne in ekspresivne, zrele in stabilne, obenem pa nič manj zaposljive in kompetentne. Še več, ocenjevalci so pri ocenjevanju njihove delovne uspešnosti in pripadnosti bolj popustljivi, če so seznanjeni z njihovim očetovskim statusom (glej: Benard in Correl, 2010).

${ }^{4}$ Za pojav, imenovan »kar je lepo, je dobro«, je značilno implicitno pripisovanje pozitivnih socialnih lastnosti, intelektualnih sposobnosti, mentalnega zdravja ter celo integritete lepim osebam.

${ }^{5} \mathrm{Na}$ primer, v omenjeni raziskavi, kjer je Biernat s sodelavkama (2010) preverjala model premičnih standardov, ni našla podpore hipotezi o prednosti žensk na žensko-tipskih delovnih mestih (konkretno, pregledovala je formalne in neformalne zapiske za delovno mesto izvršnega/ne tajnika/ce).

${ }^{6}$ Prepovedni stereotipi glede na izsledke raziskav torej ne zajemajo vseh agentnih vedenj; potrebne so nadaljnje raziskave, ki bi pojasnile, katera agentna vedenja imajo pozitiven učinek in katera negativen za ženske na moško-tipskih delovnih mestih.

${ }^{7}$ Možnost ocene uspešne menedžerske kot sovražne (antikomune), nepriljubljene in neprijetne, je zmanjšala občutek lastne nekompetentnosti pri ženskah, hkrati pa je pozitivna povratna informacija o lastnem menedžerskem potencialu prav tako zmanjšala negativno oceno uspešne menedžerke.

${ }^{8}$ Množico ukrepov te vrste bi lahko problematizirali, saj na račun pravičnosti promovirajo superiorno delovno uspešnost (angl. overperformance) kot orodje premagovanja negativnih učinkov diskriminacije pri ocenjevanju dela.

\section{Literatura}

Aberson, C. L., Healy, M. in Romero, V. (2000). Ingroup bias and self-esteem: A meta-analysis. Personality and Social Psychology Review, 4(2), 157-173.

Allen, T. J., Sherman, J. W., Conrey, F. R. in Stroessner, S. J. (2009). Stereotype strength and attentional bias: Preference for confirming versus disconfirming information depends on processing capacity. Journal of Experimental Social Psychology, 45(5), 1081-1087.

Avsec, A. (2002). Stereotipi o moških in ženskih osebnostnih lastnostih. Psihološka obzorja, 35(2), 23-35.

Benard, S. in Correll, S. J. (2010). Normative discrimination and the motherhood penalty. Gender \& Society, 24(5), 616-646.

Benard, S., Paik, I. in Correl, J. S. (2008). Cognitive bias and the motherhood penalty. Hasting Law Journal, 59, 1359-1388.

Biernat, M. (1995). The shifting standards model: Implications of stereotype accuracy for so- cial judgment. V Y. T. Lee, L. J. Jussim in C. R. Mccauley (ur.), Stereotype accuracy: Toward appreciating group differences (str. 87-114). Washington, DC, ZDA: American Psychological Association.
Biernat, M., Fuegen, K. in Kobrynowicz, D. (2010). Shifting standards and the inference of incompetence: Effects of formal and informal evaluation tools. Personality and Social Psychology Bulletin, 36(7), 855-868.

Bobbitt-Zeher, D. (2011). Gender discrimination at work connecting gender stereotypes, institutional policies, and gender composition of workplace. Gender \& Society, 25(6), 764-786.

Cashdan, E. (1998). Are men more competitive than women? British Journal of Social Psychology, 27(2), 213-229.

Conway, M. in Vartanian, L. R. (2000). A status account of gender stereotypes: Beyond communality and agency. Sex Roles, 43(3/4), 181-199.

Crosby, F. (1984). The denial of personal discrimination. American Behavioral Scientist, 27(3), 371-386.

Cundiff, J. L. in Vescio, T. K. (2016). Gender stereotypes influence how people explain gender disparities in the workplace. Sex Roles, 75(3), 126-138.

Deaux, K. in Emswiller, T. (1974). Explanations of successful performance on sex-linked tasks: What is skill for the male is luck for the female. Journal of Personality and Social Psychology, 29(1), 80-85.

Derks, B., Van Laar, C. in Ellemers, N. (2016). The queen bee phenomenon: Why women leaders distance themselves from junior women. The Leadership Quarterly, 27(3), 456-469.

Dovidio, J. F., Hewstone, M., Glick, P. in Esses, V. M. (2010). Prejudice, stereotyping and discrimination: Theoretical and empirical overview. V J. F. Dovidio, M. Hewstone, P. Glick in V. M. Esses (ur.), The SAGE handbook of prejudice, stereotyping and discrimination (str. 3-29). London, Združeno Kraljestvo: Sage Publications.

Eagly, A. H. in Karau, S. J. (2002). Role congruity theory of prejudice toward female leaders. Psychological Review, 109(3), 573-598.

Eagly, A. H., Makhijani, M. G. in Klonsky, B. G. (1992). Gender and the evaluation of leaders: A meta-analysis. Psychological Bulletin, 111(1), 3-22.

Eagly, A. H. in Mladinic, A. (1989). Gender stereotypes and attitudes toward women and men. Personality and Social Psychology Bulletin, 15(4), 543-558.

Eagly, A. H. in Mladinic, A. (1994). Are people prejudiced against women? Some answers from reserch on attitudes, gender stereotypes, and judgement of competence. European Review of Social Psychology, 5(1), 1-34.

Eagly, A. H. in Steffen, V. J. (1984). Gender stereotypes stem from the distribution of women and men into social roles. Journal of personality and social psychology, 46(4), $735-754$.

Eagly, A. H., Wood, W. in Diekman, A. B. (2000). Social role theory of sex differences and similarities: A current appraisal. V T. Eckes in H. M. Trauter (ur.), The developmental social psychology of gender (str. 123174). Mahwah, NJ, ZDA: Lawrence Erlbaum Associates Publishers.

Elsesser, K. M. in Lever, J. (2011). Does gender bias against female leaders persist? Quantitative and qualitative data from a large-scale survey. Human Relations, 64(12), $1555-1578$. 
Fiske, S. T. (2000). Interdependence and the reduction of prejudice. Reducing prejudice and discrimination. V S. Oskamp (ur.), Reducing prejudice and discrimination (str. 115-135). Mahwah, NJ, ZDA: Larry Erlbaum Associates.

Foschi, M. (1989). Status characteristics, standards, and attributions. V J. Berger, M. Zelditch in B. Anderson (ur.), Sociological theories in progress: New formulations (str. 58-72). Newbury Park, CA, ZDA: Sage.

Foschi, M. (1998). Double standards: Types, conditions, and consequences. Advances in Group Processes, 15, 59-80.

Foschi, M. (2000). Double standards for competence: Theory and research. Annual Review of Sociology, 26, 21-42.

Foschi, M. (2006). On the application-files design for the study of competence and double standards. Sociological Focus, 39(2), 115-132.

Fuegen, K., Biernat, M., Haines, E. in Deuax, K. (2004). Mothers and fathers in the workplace: How gender and parental status influence judgments of job-related competence. Journal of Social Issues, 60(4), 737-754.

Garcia-Retamero, R. in López-Zafra, E. (2009). Causal attributions about feminine and leadership roles. Journal of Cross-Cultural Psychology, 40(3), 492-509.

Glick, P., Larsen, S., Johnson, C. in Branstiter, H. (2005). Evaluations of Sexy Women in Low- and High-Status Jobs. Psychology of Women Quarterly, 29(4), 389-395.

Goldberg, P. (1968). Are women prejudiced against women? Trans-action, 5(5), 28-30.

Halpert, J. A., Wilson, M. L. in Hickman, J. L. (1993). Pregnancy as a source of bias in performance appraisals. Journal of Organizational Behavior, 14(7), 649-663.

Hays, S. (1998). The cultural contradictions of motherhood. New Haven, CT, ZDA: Yale University Press.

Heflick, N. A., Goldenberg, J. L., Cooper, D. P. in Puvia, E. (2011). From women to objects: Appearance focus, target gender, and perceptions of warmth, morality and competence. Journal of Experimental Social Psychology, 47(3), 572-581.

Heilman, M. E. (1983). Sex bias in work settings: The lack of fit model. Research in Organizational Behavior, 5, 269-98.

Heilman, M. E. (2001). Description and prescription: How gender stereotypes prevent women's ascent up the organizational ladder. Journal of Social Issues, 57(4), 657-674.

Heilman, M. E. (2012). Gender stereotypes and workplace bias. Research in Organizational Behavior, 32, 113-135.

Heilman, M. E. in Chen, J. J. (2005). Same behavior, different consequences: Reactions to men's and women's altruistic citizenship behavior. Journal of Applied Psychology, 90(3), 431-441.

Heilman, M. E. in Eagly, A. H. (2008). Gender stereotypes are alive, well, and busy producing workplace discrimination. Industrial and Organizational Psychology, 1(4), 393-398.

Heilman, M. E. in Haynes, M. C. (2005). No credit where credit is due: Attributional rationalization of women's success in male-female teams. Journal of Applied Psychology, 90(5), 905-916.
Heilman, M. E. in Okimoto, T. G. (2007). Why are women penalized for success at male tasks? The implied communality deficit. Journal of Applied Psychology, 92(1), 81-92.

Heilman, M. E. in Parks-Stamm, E. J. (2007). Gender stereotypes in the workplace: Obstacles to women's career progress. V S. J. Correll (ur.), Social psychology of gender: Advances in group processes (str. 47-77). Bingley, Združeno Kraljestvo: Emerald Group Publishing.

Heilman, M. E. in Stopeck, M. H. (1985). Being attractive, advantage or disadvantage? Performance-based evaluations and recommended personnel actions as a function of appearance, sex, and job type. Organizational Behavior and Human Decision Processes, 35(2), 202-215.

Heilman, M. E., Wallen, A. S., Fuchs, D. in Tamkins, M. M. (2004). Penalties for success: Reactions to women who succeed at male gender-typed tasks. Journal of Applied Psychology, 89(3), 416-427.

Heilman, M. E. in Wallen, A. S. (2010). Wimpy and undeserving of respect: Penalties for men's genderinconsistent success. Journal of Experimental Social Psychology, 46(4), 664-667.

Hosoda, M., Stone-Romero, E. F. in Coats, G. (2003). Jobrelated outcomes: A meta-analysis of experimental studies. Personnel Psychology, 56(2), 431-462.

Jackson, L. A, Sullivan, L. A in Hodge, C. N. (1993). Stereotype effects on attributions, predictions, and evaluations: No two social judgments are quite alike. Journal of Personality and Social Psychology, 65(1), 69-84.

Johnson, S. K., Murphy, S. E., Zewdie, S. in Reichard, R. J. (2008). The strong, sensitive type: Effects of gender stereotypes and leadership prototypes on the evaluation of male and female leaders. Organizational Behavior and Human Decision Processes, 106(1), 39-60.

Johnston, D. D. in Swanson, D. H. (2006). Constructing the "good mother«: The experience of mothering ideologies by work status. Sex Roles, 54(7/8), 509-519.

Jussim, L., Crawford, J. T. in Rubinstein, R. S. (2015). Stereotype (in)accuracy in perceptions of groups and individuals. Current Directions in Psychological Science, 24(6), 490-497.

Kark, R., Waismel-Manor, R. in Shamir, B. (2012). Does valuing androgyny and femininity lead to a female advantage? The relationship between gender-role, transformational leadership and identification. The Leadership Quarterly, 23(3), 620-640.

Kelly, E. L., Ammons, S. K., Chermack, K. in Moen, P. (2010). Gendered challenge, gendered response: Confronting the ideal worker norm in a white-collar organization. Gender \& Society, 24(3), 281-303.

Koch, A. J., D’Mello, S. D. in Sackett, P. R. (2015). A metaanalysis of gender stereotypes and bias in experimental simulations of employment decision making. The Journal of Applied Psychology, 100(1), 128-161.

Koenig, A. M., Eagly, A. H., Mitchell, A. A. in Ristikari, T. (2011). Are leader stereotypes masculine? A metaanalysis of three research paradigms. Psychological Bulletin, 137(4), 616-642. 
Latu, I. M., Stewart, T. L., Myers, A. C., Lisco, C. G., Estes, S. B. in Donahue, D. K. (2011). What we »say« and what we "think" about female managers: Explicit versus implicit associations of women with success. Psychology of Women Quarterly, 35(2), 252-266.

Lippa, R. A. (2001). On deconstructing and reconstructing masculinity-femininity. Journal of Research in Personality, 35(2), 168-207.

Lopez-Zafra, E. in Garcia-Retamero, R. (2012). Do gender stereotypes change? The dynamic of gender stereotypes in Spain. Journal of Gender Studies, 21(2), 169-183.

Lyness, K. S. in Heilman, M. E. (2006). When fit is fundamental: Performance evaluations and promotions of upper-level female and male managers. Journal of Applied Psychology, 91(4), 777-785.

Mavin, S. in Williams, J. (2013). Women's impact on women's careers in management: Queen bees, female misogyny, negative intra-relations and solidarity behaviours. V S. Vinnicombe, R. J. Burke, S. Blake-Beard, in L. L. Moore (ur.), Handbook of research on promoting women's careers (str. 178-195). Cheltenham, Združeno kraljestvo: Edward Elgar.

Moss-Racusin, C. A., Phelan, J. E. in Rudman, L. A. (2010). When men break the gender rules: Status incongruity and backlash against modest men. Psychology of Men \& Masculinity, 11(2), 140-151.

Niederle, M. in Vesterlund, L. (2011). Gender and competition. Annual Review of Economics, 3(1), 601-630.

Parks-Stamm, E. J., Heilman, M. E. in Hearns, K. A. (2008). Motivated to penalize: Women's strategic rejection of successful women. Personality and Social Psychology Bulletin, 34(2), 237-247.

Phelan, J. E., Moss-Racusin, C. A. in Rudman, L. A. (2008). Competent yet out in the cold: Shifting criteria for hiring reflect backlash toward agentic women. Psychology of Women Quarterly, 32(4), 406-413.

Riach, P. A. in Rich, J. (2002). Field experiments of discrimination in the market place. The Economic Journal, 112, F480-F518.

Ridgeway, C. L. (1997). Interaction and the conservation of gender inequality: Considering employment. American Sociological Review, 26(2), 218-235.

Rudman, L. A. in Phelan, J. E. (2008). Backlash effects for disconfirming gender stereotypes in organizations. Research in Organizational Behavior, 28, 61-79.

Schein, V. E. (2001). A global look at psychological barriers to women's progress in management. Journal of Social Issues, 57(4), 675-688.

Sechrist, G. B. in Delmar, C. (2009) When do men and women make attributions to gender discrimination? The role of discrimination source. Sex Roles, 61(9/10), 607-620.

Sherman, J. W., Stroessner, S. J., Conrey, F. R. in Azam, O. A. (2005). Prejudice and stereotype maintenance processes: Attention, attribution, and individuation. Journal of Personality and Social Psychology, 89(4), 607-622.
Swim, J., Borgia, E., Maruyama, G. in Myers, D. G. (1989). Joan McKay versus John McKay: Do gender stereotypes bias evaluations? Psychological Bulletin, 105(3), 409-429.

Vinkenburg, C. J., VanEngen, M. L., Eagly, A. H. in JohannsenSchmidt, M. C. (2011). An exploration of stereotypical beliefs about leadership styles: Is transformational leadership a route to women's promotion? The Leadership Quarterly, 22(1), 10-21.

Wetherell, M., Stiven, H. in Potter, J. (1987). Unequal egalitarianism: A preliminary study of discourses concerning gender and employment opportunities. British Journal of Social Psychology, 26(1), 59-71.

Wilde, A. in Diekman, A. B. (2005). Cross-cultural similarities and differences in dynamic stereotypes: A comparison between Germany and the United States. Psychology of Women Quarterly, 29(2), 188-196. 